\title{
Pulse Probiotic Administration Induces Repeated Small Intestinal Muc3 Expression in Rats
}

\author{
NATALIE S. DYKSTRA, LUCIE HYDE, DIYA ADAWI, DINA KULIK, SIV AHRNE, GORAN MOLIN, BENGT JEPPSSON, \\ ALEXANDER MACKENZIE, AND DAVID R. MACK
}

\author{
Children's Hospital of Eastern Ontario Research Institute [N.S.D., L.H., D.K., A.M., D.R.M.], Ottawa, Ontario K1H 8L1, Canada; \\ Department of Surgery [D.A., B.J.], Malmo University, Malmo SE-205 02, Sweden; Department of Food Science [S.A., G.M.], Lund \\ University, Lund S-221 00, Sweden; Department of Pediatrics [A.M., D.R.M.], University of Ottawa, Ottawa, Ontario K1H 8M5, Canada
}

\begin{abstract}
Upon ingestion, probiotics may act to protect the host through a number of protective mechanisms including modulation of genes involved in intestinal innate mucosal defense such as epithelial cell-derived mucin glycoproteins and inhibitor of apoptosis proteins. To determine the specificity of effect and sustainability of response in vivo, Lactobacillus plantarum 299v (Lp299v), Lactobacillus rhamnosus R0011 (LrR0011), and Bifidobacterium bifidum R0071 (BbR0071) were added repeatedly or intermittently to the drinking water of Sprague-Dawley rats. After killing the rats via $\mathrm{CO}_{2}$ suffocation, Muc2, Muc3, neuronal apoptosis inhibitor protein (NAIP), human inhibitor of apoptosis protein 1/cellular inhibitor of apoptosis 2 (HIAP1/cIAP2), and human inhibitor of apoptosis protein 2/cellular inhibitor of apoptosis 1 (HIAP2/cIAP1) mRNA and protein levels were analyzed via RT-PCR and immunohistochemistry. Live Lp299v, BbR0071, and LrR0011 increased Muc3 protein and mRNA expression in jejunum and ileum. Heat-killed and a nonadherent derivative of Lp299v failed to induce Muc3 expression. Lp299v did induce expression of HIAP2/cIAP1 and NAIP expression. Muc3 mucin expression was elevated for $5 \mathrm{~d}$ after oral administration of Lp299v; however, this effect was not sustained despite ongoing daily ingestion of a probiotic. Intermittent pulse ingestion of probiotics, however, was found to repeatedly increase Muc3 expression. We conclude that selected probiotics can induce protective genes of mucosal intestinal epithelial cells, an effect that is reproducible with pulse probiotic administration. (Pediatr Res 69: 206-211, 2011)
\end{abstract}

$\mathrm{P}$ robiotics are living organisms that improve the health of the host upon ingestion (1). One mechanism whereby probiotics exert their influence is through enhancement of intestinal barrier function (1). The intestinal mucosal barrier consists of both the intestinal epithelial cell (IEC) and the supramucosal mucus layer whose major organic component is intestinal cell-derived mucins. Mucins are complex glycoproteins that act to limit access to IECs by both by creating a physicochemical barrier and through enteropathogen IEC receptor mimicry $(2,3)$.

Probiotics have a multitude of effects in germ-free animals and sterile cell culture system. However, to determine whether mucosal protection can be enhanced exogenously by probiotics, use of specific pathogen-free rats offers a

Received July 29, 2010; accepted October 16, 2010.

Correspondence: David Mack, M.D., Children's Hospital of Eastern Ontario, 401 Smyth Road, Ottawa, Ontario, Canada K1H 8L1; e-mail: dmack@cheo.on.ca

Supported through research grants from Lallemand Inc. (Montreal, Quebec) and Probi AB (Lund, Sweden). method to study probiotic administration into an established microbial environment.

In cell cultures, selected probiotic strains attenuate the stress-induced death of IECs. IEC homeostasis is maintained in the gastrointestinal tract mainly via apoptosis, via important regulators of apoptosis including members of the inhibitor of apoptosis protein (IAP) family (4). IAPs have a number of other roles including regulating proliferation and modulation of inflammatory signaling and immunity (5). IECs that are lost through a physiologic process are replenished at an equally rapid rate in villi crypts, on average every $3-5 \mathrm{~d}(4,6)$. With some of the best clinical evidence for probiotic benefit being that of attenuating viral enteritis (7), and with the small intestinal IECs constituting a crucial interface between luminal contents and the host, we hypothesized that probiotics will protect IECs by modulating expression of mucin and proteins that regulate apoptosis. Accordingly, we evaluated the importance of live, viable probiotics and their sustainability of enhancing IEC protective functions after administration into an established rodent microbiota.

\section{MATERIALS AND METHODS}

Bacteria and growth conditions. Bacteria studies included Lactobacillus plantarum strain 299v (Lp299v; supplied by Dr. Siv Ahrne, University of Lund, Lund Sweden). An adherent negative derivative strain of Lp299v named L. plantarum adh- (Lpadh-; supplied by Dr. Siv Ahrne) is a spontaneous mutant of Lp299v that lacks adherin. RFLP analysis did not detect differences between Lp299v and its derivative Lpadh- (8). Other strains included L. rhamnosus strain R0011 and Bifidobacterium bifidum (LrR0011 and BbR0071; supplied by Dr. Thomas Tompkins, Institut Rosell Inc., Montreal, Quebec). Strains were stored at $-80^{\circ} \mathrm{C}$ until grown overnight at $37^{\circ} \mathrm{C}$ in $40 \mathrm{~mL}$ of either Lactobacilli MRS broth (Becton Dickinson Canada Inc., Oakville, ON) or Reinforced Clostridial Media broth (Becton Dickinson Canada Inc.). Bacteria were harvested by centrifugation as previously described (3). Heat-killed strains were boiled for $30 \mathrm{~min}$ a day for a total of $3 \mathrm{~d}$. Bacteria were then plated in triplicate and incubated for $24 \mathrm{~h}$ at $37^{\circ} \mathrm{C}$ to ensure there was no growth.

Animals. Specific pathogen-free male Sprague-Dawley rats (Charles River Laboratories Inc., Montreal, PQ) weighing $250 \mathrm{~g}$ were acclimatized to the

Abbreviations: BbR0071, Bifidobacterium bifidum R0071; CFU, colony forming units; HIAP1/cIAP2, human inhibitor of apoptosis protein 1/cellular inhibitor of apoptosis 2; HIAP2/cIAP1, human inhibitor of apoptosis protein 2/cellular inhibitor of apoptosis 1; IAP, inhibitor of apoptosis protein; IEC, intestinal epithelial cell; Lpadh-, Lactobacillus plantarum adh-; Lp299v, Lactobacillus plantarum 299v; LrR0011, Lactobacillus rhamnosus R001; NAIP, neuronal apoptosis inhibitor protein; XIAP, $\mathrm{x}$-linked inhibitor of apoptosis 
regular vivarium at the University of Ottawa for a period of $5 \mathrm{~d}$ under standard conditions. Standard diet of food and water was provided ad libitum. Probiotics were quantified and added to the drinking water of Sprague-Dawley rats to ensure that $10^{7}$ colony forming units $(\mathrm{CFU})$ or $10^{9} \mathrm{CFU}$ of probiotics were being ingested per day, depending on treatment protocol. C57/B16 mice were used to determine whether the effects noted were similar in mice. Probiotics were administered to mice via daily gavage. Experiments to evaluate mucin expression after rectal application of probiotics were performed in Sweden (D.R.M., D.A.). Specific pathogen-free Sprague-Dawley rats $(\mathrm{M}+\mathrm{B}$ A/S, DK-8680 Ry, Denmark) were housed at constant $22^{\circ} \mathrm{C}$ temperature and humidity with a controlled 12-h light/dark cycle. Rats had free access to a standard pellet diet (R3; Lactomin, Stockholm, Sweden) and sterilized tap water. Rats received daily enemas through a feeding tube (CM08; Unomedical A/S, Denmark) containing $3 \times 10^{9} \mathrm{CFU}$ Lp299v or water alone for up to $7 \mathrm{~d}$. Experimentation was performed with the approval of the Animal Care Committee at the University of Ottawa or the University of Lund.

Modulation of gene expression in vivo. Rats and mice were divided into groups on the basis of bacteria administered, dose, and the total number of treatment days. Animals were killed by means of $\mathrm{CO}_{2}$ suffocation. In Sweden, rats were killed using a s.c. injection of a (1:12) mixture of Hyponorm (Division of Janssen-Cilas Ltd., Janssen Pharmaceutica, Boerse, Belgium), Dormicum (F. Hoffman-La Roche AG, Basel, Switzerland) in a dose of 0.15 $\mathrm{mL} / 100 \mathrm{~g}$. Sections of the proximal jejunum, distal ileum, proximal colon, and distal colon were excised, flushed with PBS, and opened so that mucosal scrapings could be obtained. Scrapings were placed in RNAlater stabilizing reagent (Qiagen Inc., Mississauga, ON) and stored at $-20^{\circ} \mathrm{C}$ until RNA extraction. Tissues were homogenized via a QiaShredder column (Qiagen Inc., Mississauga, ON), and RNA was extracted using RNeasykit (Qiagen Inc.) according to the manufacturer's protocol. For groups receiving rectal probiotics, total RNA was isolated from distal colon mucosal scrapings using the guanidine isothiocyanate-cesium chloride ultracentrifugation technique (2). RNA pellets were suspended in $0.3 \mathrm{M}$ sodium acetate and precipitated with 2.5 volumes of $100 \%$ ethanol and stored at $-80^{\circ} \mathrm{C}$ until analysis.

RT-PCR transcript analysis. Probes (IDT Inc., Coralville, IA) and primers were designed for $M u c 1, M u c 2, M u c 3$, human inhibitor of apoptosis protein 1 (HIAP1/cIAP2), human inhibitor of apoptosis protein 2 (HIAP2/cIAP1), neuronal apoptosis inhibitor protein (NAIP), and X-linked inhibitor of apoptosis protein $(X I A P)$ using Primer Express version 2.0 (Applied Biosystems, Foster City, CA) are detailed in Table 1. Real-time RT-PCR was then used to quantify expression levels, normalized to rodent GAPDH expression levels (Applied Biosystems). Samples were plated in triplicate wells in a MicroAmp Optical 96-well Reaction Plate (Perkin Elmer, Norwalk, CT) with added no template control wells and analyzed using the ABI Prism 7700 Sequence Detection System (Applied Biosystems).
Protein detection. Rodent anti-Muc3 antibody (\#6279, Dr. G. Xu and Dr. I. Khatri, Hospital for Sick Kids, Toronto, Canada) targeting $\mathrm{COOH}$-terminal region was used to detect rat Muc3 protein expression (9). RIAP1 antibody to the rodent homologues of both HAIP1/cIAP2 at $70 \mathrm{kD}$ on SDS-Page gels and HiAP2/cIAP1 at $68 \mathrm{kD}$ was a gift (Aegera Therapeutics Inc., Montreal, PQ). To detect proteins of interest, sections of intestine were impregnated with $30 \%$ sucrose overnight and then cut at $10 \mu \mathrm{m}$ using a Microm HM 500 OM cryostat (Thermo Scientific, Walldorf, Germany). Sections were then boiled in citrate buffer for $20 \mathrm{~min}$, and endogenous peroxidase was removed with $3 \%$ $\mathrm{H}_{2} \mathrm{O}_{2}$ and after a 5-min tris buffered saline (TBS) wash, suppressed using a peroxidase blocking solution (Dako, Mississauga, ON) for $10 \mathrm{~min}$. Sections were incubated in a humid chamber with the undiluted anti-Muc3 antibody for $2 \mathrm{~h}$, washed, and incubated for $30 \mathrm{~min}$ with donkey anti-rabbit IgG ECL antibody, HRP-conjugated (GE Healthcare, Piscataway, NJ). Sections were developed using the 3,3'-diaminobenzidine Enhanced Liquid Substrate System (Sigma Chemical Co.-Aldrich Canada, Oakville, ON) with a Harris hemotoxylin solution counterstain (Fisher Scientific, Ottawa, ON). Slides were differentiated in $0.2 \%$ acid/alcohol solution and blued in a solution of $2 \%$ aqueous $\mathrm{LiCO}_{3}$. The slides were then mounted with Permount (Fisher Scientific) and examined for increased staining using the Axioskop 2 plus microscope (Carl Zeiss Canada, Toronto, ON) visualized with Northern Eclipse Software, version 6.0 (Empix Imaging Inc., Mississauga, ON). Additional samples of rat jejunum were assessed using immunofluorescence to improve visualization. These samples were collected and processed as previously described with the exception of using goat anti-mouse IgG Alexa Fluor488 antibody (Invitrogen, Carlsbad, CA) at 1:500 dilution.

Western blotting. Protein isolates were analyzed using the MiniPROTEAN III gel system (BioRad Laboratories, Hercules, CA) with SDSPage using $7.5 \%$ bisacrylamide gel including a $4 \%$ stacking gel. Protein aliquots were heated to $70^{\circ} \mathrm{C}$ for $10 \mathrm{~min}$ and were then quick chilled on ice before loading. Following transfer and 5\% milk blocking of the blots, polyvinylidene fluoride membranes were washed for $1 \mathrm{~h}$ in Tris-PBS with Tween, incubated with primary antibody overnight followed by washes and incubation with ECL anti-mouse or Anti-rabbit IgG secondary antibody (GE Healthcare) for $1 \mathrm{~h}$. The ECL Plus Western Blotting Detection System (GE Healthcare) was used for detection of secondary antibody, and membranes were exposed to ECL Plus Hyperfilm (GE Healthcare) and visualized using the IVIS imaging equipment with LivingImage Software (Caliper LifeSciences, Hopkinton, MA). Files were analyzed using ImageJ, an image processing software program available through the National Institutes of Health (http://rsbweb.nih.gov/ij/index.html). Densitometric data were generated through a calculation of total area under the curve.

Statistical analysis. Descriptive statistics were calculated according to treatment group. Summary statistics were expressed as the mean $\pm \mathrm{SD}$, and

Table 1. TaqMan RT-PCR primer and probe sequences

Gene Sequence

\begin{tabular}{|c|c|}
\hline Gene & Sequence \\
\hline \multicolumn{2}{|l|}{ Rat Muc1 } \\
\hline Forward primer & 5' CGGCCAACTTGTAGGAGCAA 3' \\
\hline Reverse primer & 5' AGTGGACTGCTGGAGCCAACT 3' \\
\hline Probe & 6-FAM-CACCCTACCCACTCGGGCAGTGG-TAMRA \\
\hline \multicolumn{2}{|l|}{ Rat Muc2 } \\
\hline Forward primer & 5' GGTGGCCTTCAAATCAGGTG 3' \\
\hline Reverse primer & 5' AGGGTTTGAAGATGGAGAAGCTC 3' \\
\hline Probe & 6-FAM-AGTGTGTTGCTCAATGAAATGGAGGTGTCC-TAMRA \\
\hline \multicolumn{2}{|r|}{ 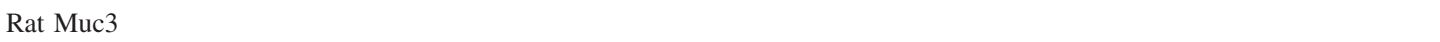 } \\
\hline Forward primer & 5' CTCGTGGGAGCCGGG 3' \\
\hline Reverse primer & 5' AGTGGACGGAGAACACAGCG 3' \\
\hline Probe & 6-FAM-TGGCAGTGCTGTTGGTGATTCTTGTGA-TAMRA \\
\hline \multicolumn{2}{|r|}{ 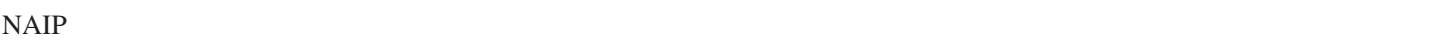 } \\
\hline Forward primer & 5' GCCATTTTATGTCCAAGGGATATC 3' \\
\hline Reverse primer & 5' CTTCССААТTТССТАААСАСТСА $3^{\prime}$ \\
\hline Probe & 6-FAM-CTGTACCGTGTCCTGTTTACCTGTAAAGACAAAGC-TAMRA \\
\hline \multicolumn{2}{|l|}{ HIAP1/cIAP2 } \\
\hline Forward primer & $5^{\prime}$ TGGAGATGATCCATGGGTTCA 3' \\
\hline Reverse primer & 5' GAACTCCTGTCCTTTAATTCTTATCAAGT 3' \\
\hline Probe & 6-FAM-CTCACACCTTGGAAAACCACTTGGCATG-TAMRA \\
\hline \multicolumn{2}{|l|}{ HIAP2/cIAP1 } \\
\hline Forward primer & 5' TCTGGAGATGATCCATGGGTAGA 3' \\
\hline Reverse primer & $5^{\prime}$ TGGCCTTTCATTCGTATCAAGA 3' \\
\hline Probe & 6-FAM-CTCACACCTTGGAAACCACTTGGCATG-TAMRA \\
\hline
\end{tabular}




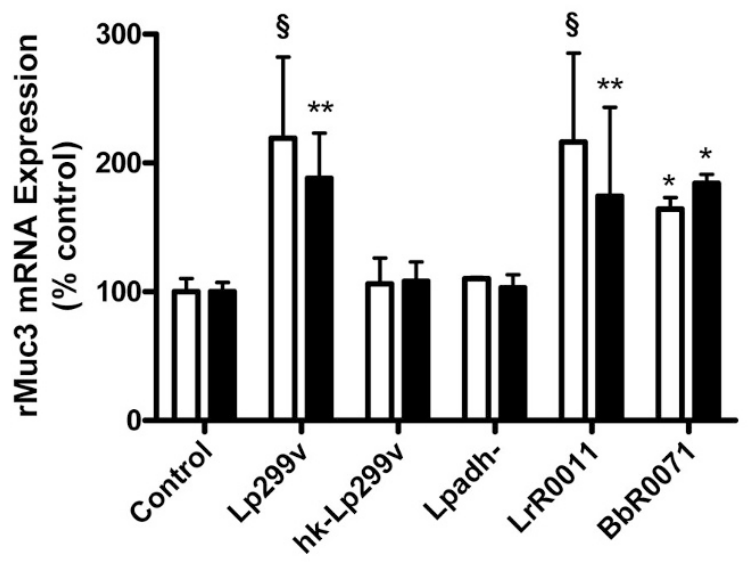

Figure 1. Regional intestinal mucin mRNA expression in rats after oral ingestion of live probiotic microbes and heat-killed Lp299v. Expression levels of Muc3 mRNA in the jejunum ( $\square$ ) and ileum ( $\square$ ) is shown. Data are presented as a percentage of normalized Muc3 expression in control animals not receiving probiotics. Values represent mean $\pm \mathrm{SD}, n=26, * p<0.05$, ${ }^{* *} p<0.01,{ }^{8} p<0.0001$. Heat-killed Lp299v (hk-Lp299v), $n=16$.

$t$ test was used to compare data between two groups and ANOVA between multiple groups. For those ANOVA analyses reaching significance, differences between groups was analyzed using Tukey's post hoc analysis. All reported $p$ values are two-sided and were declared significant when they reached a 0.05 probability level. Analyses were performed using Statview 5.0.1 (SAS Institute, Cary, NC) and GraphPad Prism 4.03 (GraphPad Software Inc., LA Jolla, CA).

\section{RESULTS}

Lactobacillus plantarum 299v, Lactobacillus rhamnosus R0011, and Bifidobacterium bifidum R0071 up-regulate rat mucin in a site-specific manner. The expression of rat Muc3 mucin was assessed in distinct regions along the intestinal tract after $2 \mathrm{~d}$ of specific probiotic ingestion at $10^{7} \mathrm{CFU} / \mathrm{d}$ (Fig. 1). Ingestion of live microbes led to an increase in $M u c 3$ transcript in both jejunum and ileum in all animals except those ingesting Lpadh-. Immunohistochemistry performed on rat jejunal segments supported these findings with demonstration of increased Muc3 protein expression after $2 \mathrm{~d}$ of Lp299v ingestion (Fig. 2, B2). This effect was not observed in either controls receiving water only (Fig. 2, B1) or sections from rats receiving Lpadh-. Expression of other mucin genes was evaluated. Mucl expression levels were increased in jejunal segments but not in the other intestinal segments. Expression of Muc2 mRNA was not increased above that found in controls in either jejunum or ileum (Mucl and $M u c 2$ results not shown). Muc2 and Muc3 expression did not change significantly in proximal and distal colonic segments after oral ingestion of probiotics at $10^{7} \mathrm{CFU} / \mathrm{d}$. We also failed to note any additive effect with concurrent addition of both BbR0071 and LrR0011 each at $10^{9} \mathrm{CFU} / \mathrm{d}$ with regard to $M u c 3$ or $M u c 2$ expression in either the colon or small intestine (results not shown).

To evaluate whether delivery route affects mucin expression, administration of rectal enemas containing Lp299v were also evaluated. Distal colon Muc2 mRNA expression was increased $(160 \%$ control $\pm 50, p<0.05)$ compared with water controls (Fig. 3), but neither Muc1 nor Muc3 mRNA expression of distal colon segments was increased after $2 \mathrm{~d}$ of

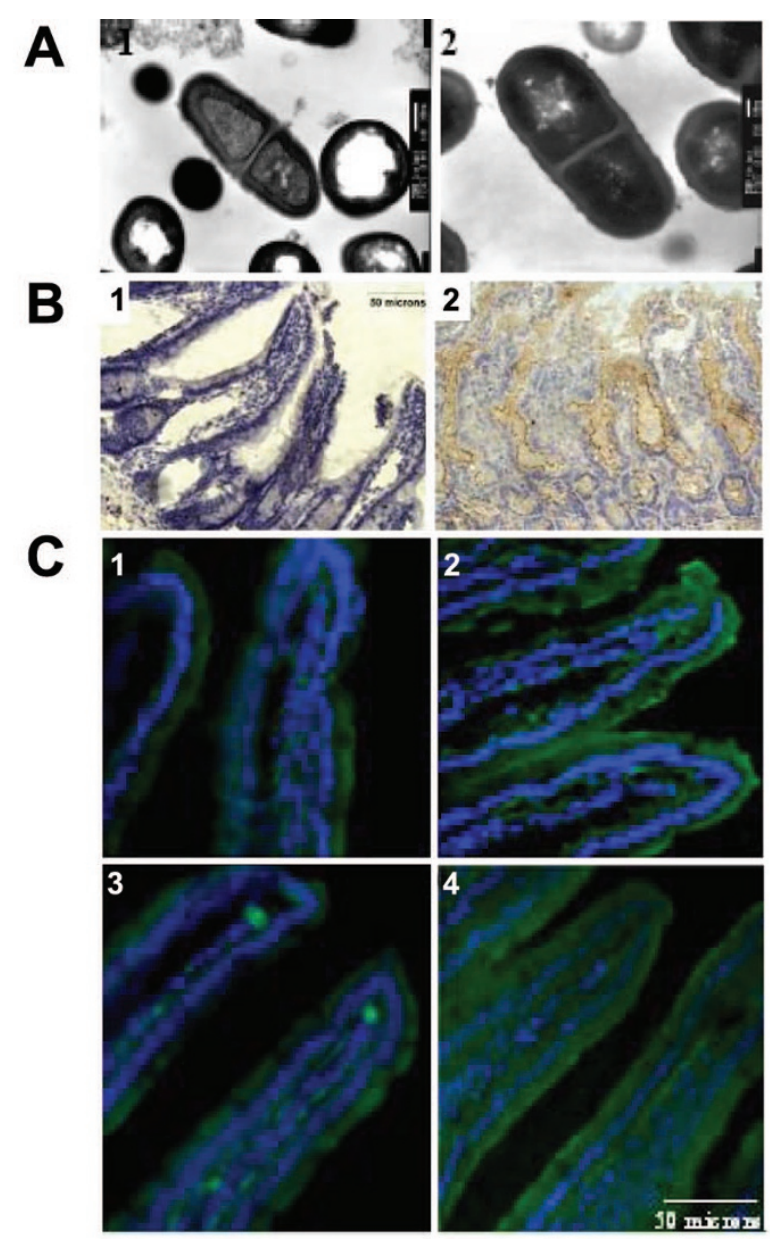

Figure 2. Lp299v and Muc3 tissue expression. (A) Photomicrographs of live Lp299v, magnification $\times 40 \mathrm{~K}$, barred scale of $200 \mathrm{~nm}$ length (1), and heat-killed Lp299v, magnification $\times 50 \mathrm{~K}$, barred scale of $100 \mathrm{~nm}$ length (2). (B) Muc3 immunohistochemistry photomicrographs depict rat jejunal segments after $2 \mathrm{~d}$ of water consumption in the absence of probiotic supplementation (1) and after $2 \mathrm{~d} 10^{9} \mathrm{CFU} / \mathrm{d}$ Lp299v administration (2). Images at $\times 200$ magnification. $(C)$ Muc3 immunofluorescence of rat jejunal segments after $2 \mathrm{~d}$ of water ingestion in the absence of probiotic supplementation (1), $2 \mathrm{~d}$ of Lp299v (2), 20 d of Lp299v (3), and after receiving probiotic pulse therapy of $2 \mathrm{~d}$ of BbR0071, $8 \mathrm{~d}$ of water, and then $2 \mathrm{~d}$ of Lp299v (4). Images at $\times 200$ magnification.

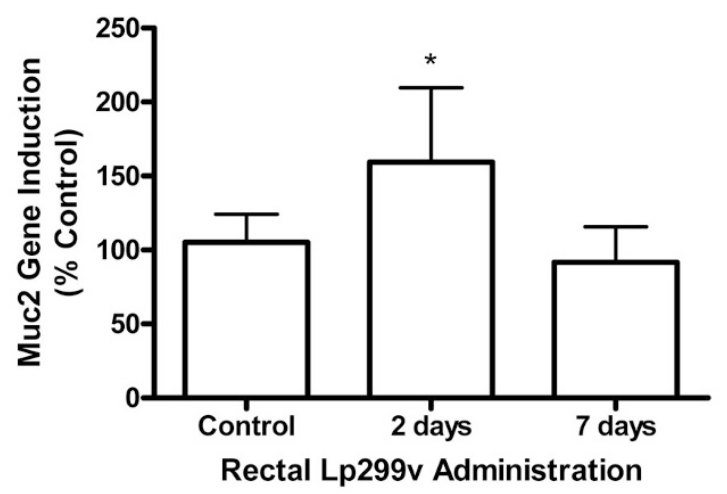

Figure 3. Distal colonic Muc2 mRNA expression. Muc2 expression after rectal $3 \times 10^{9} \mathrm{CFU}$ Lp299v or water in control animals. Values represent mean $\pm \mathrm{SD}, * p<0.05$. 


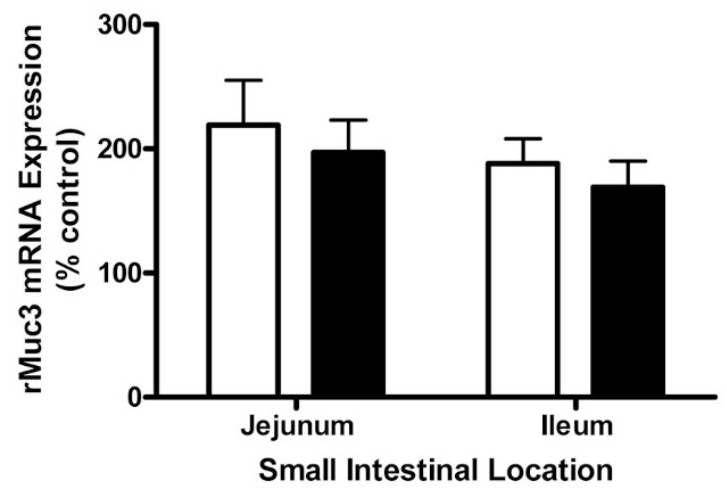

Figure 4. Small intestinal Muc3 mRNA expression with variable Lp299v dosing. Rats ingested $10^{7} \mathrm{CFU}$ per day of Lp299v ( $\square$ ) or $10^{9} \mathrm{CFU}$ per day (ם) for $2 \mathrm{~d}$. Values represent $\%$ control, mean $\pm \mathrm{SD}, n=14, p>0.05$.

Lp299v rectal enemas (results not shown). Moreover, as shown in Figure 3, this effect had tapered to baseline expression level by $7 \mathrm{~d}(92 \%$ control \pm 24$)$.

Heat-killed Lp299v does not induce mucin expression. Heat-killed Lp299v were plated onto Lactobacillus MRS agar and were determined to be nonviable and intact (Fig. 2, A2). As shown in Figure 1, heat-killed Lp299v administered orally to rats for $2 \mathrm{~d}$ failed to up-regulate $M u c 3$ expression in jejunum $(106 \%$ control \pm 12$)$ or ileum $(108 \%$ control \pm 4$)$.

Probiotic-induced mucin gene modulation in small intestine is not dose-dependent. To investigate the effect of larger inoculum on small intestinal mucin expression levels, animals were given either $10^{7} \mathrm{CFU} / \mathrm{d}$ or $10^{9} \mathrm{CFU} / \mathrm{d}$ of Lp299v. Both doses significantly altered Muc3 expression levels; however, there was no greater expression between doses in either the jejunum or ileum (Fig. 4; low dose versus high dose, $p>0.05$ ).

Lp299v modulates the expression of NAIP and HIAP2/ cIAP1 in vivo. NAIP, HIAP1/CIAP2, HIAP2/CIAP1, and XIAP were examined in Sprague-Dawley rats and C57/B16 mice after $2 \mathrm{~d}$ of $10^{9} \mathrm{CFU} / \mathrm{d}$ of Lp299v. In C57/B16 mice, HIAP2/ cIAP1 (158\% control $\pm 31, p<0.001$, Fig. 5A, bar 4$)$ and NAIP (151\% control $\pm 36, p<0.0001$, Fig. 5A, bar 2) mRNA expression levels were greater than in control mice receiving water alone. In contrast, jejunal HIAP1/cIAP2 (102\% control \pm 18 , Fig. 5A, bar 3 ) and XIAP (98\% control \pm 22 , Fig. 5A, bar 5) mRNA levels were similar to water administered control animals. Results from the rat treatment groups demonstrated the same trend. For all genes evaluated in rat and mice, Lpadh-failed to induce expression levels beyond control values.

Sprague-Dawley rat segments were assessed for IAP expression. The rodent homologues of HIAP2/cIAP1 levels in the rat jejunum increased $\sim 2$-fold after a 2-d course of Lp299v (Fig. 5B, compare lane 2 at $68 \mathrm{kD}$ ) compared with control animals receiving water (Fig. 5B, compare lane 4). In contrast, no significant HIAP2/cIAP1 protein expression was noted in ileal samples from animals receiving Lp299v (Fig. 5B, compare lane 1 at $68 \mathrm{kD}$ ) versus controls (Fig. 5B, compare lane 1). Similarly, HIAP1/cIAP2 (70 kD) remained unchanged.

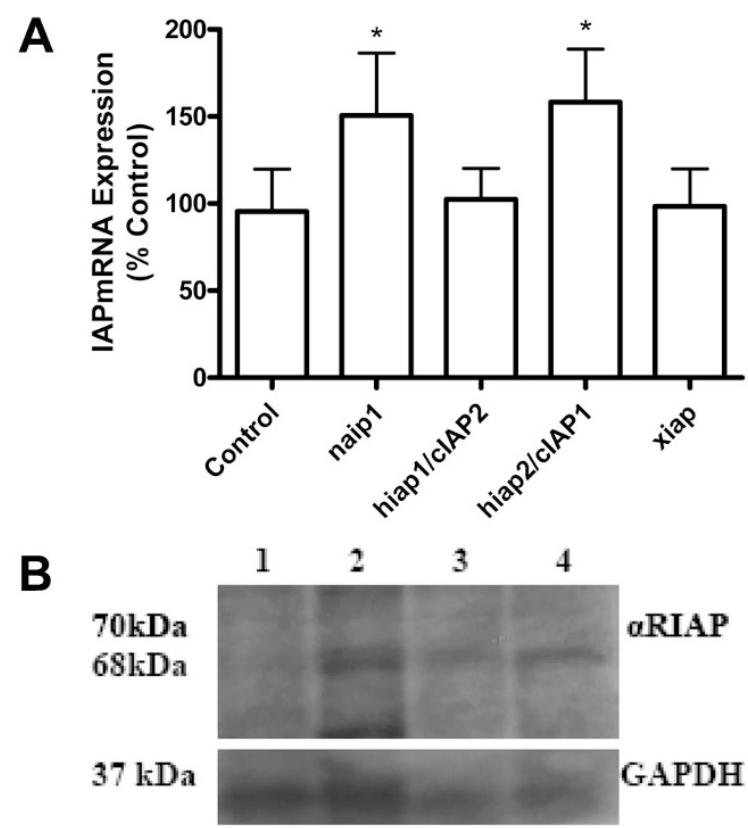

Figure 5. NAIP and HIAP2/cIAP1 are increased in response to $2 \mathrm{~d}$ treatment with Lp299v in vivo. mRNA expression in the mouse jejunum is shown in (A). Values shown represent mean \pm SD for four independent experiments, run in triplicate. ${ }^{*} p<0.05, n=30$ total. (B) Western blotting of jejunal and ileal rat protein extracts. Lanes (from left to right): 1, treated ileum; 2, treated jejunum; 3 , ileum control; 4, jejunum control.

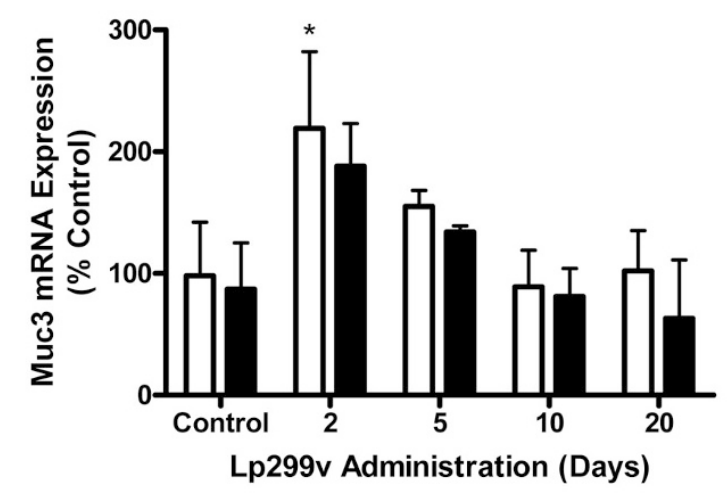

Figure 6. Mucin gene expression after daily probiotic administration. Levels of Muc3 mRNA from the jejunum $(\square)$ and ileum ( $\square$ ) shown relative to the water control group. Values represent mean $\pm \mathrm{SD}, n=45$ total, $* p<0.05$.

Daily oral administration of a single probiotic microbe is not effective in sustaining Muc3 up-regulation. To evaluate the sustainability of probiotic-induced response, rats received $10^{7} \mathrm{CFU} / \mathrm{d}$ of Lp299v for 2 to $20 \mathrm{~d}$ before killing. Lp299v was shown to significantly up-regulate $M u c 3$ after $2 \mathrm{~d}$ in the jejunum and ileum (219\% control \pm 63 and $165 \%$ control \pm 63 respectively, $p<0.05$ ) with expression decreasing after $5 \mathrm{~d}$ ( $155 \%$ control \pm 13 and $134 \%$ control \pm 5 in the jejunum and ileum, respectively). Following, both 10 and $20 \mathrm{~d}$ of daily probiotic administration, $М u c 3$ expression levels were similar to controls (Fig. 6). Immunofluorescence of the rat jejunum demonstrated Muc3 expression was increased after $2 \mathrm{~d}$ of Lp299v treatment (Fig. 2, C2) compared with both the con- 


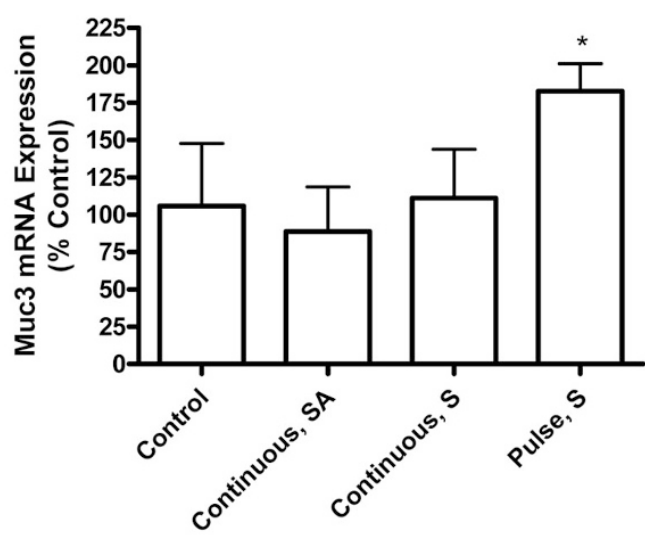

Figure 7. Modulation of Muc3 mRNA levels using various administration protocols. Control animals (Control) received water. Continuous, single probiotic agent (Continuous, SA) animals received $10 \mathrm{~d}$ of Lp299v before sacrifice. Continuous, sequential (Continuous, S) animals received BbR0071 for $10 \mathrm{~d}$ and then $2 \mathrm{~d}$ of Lp299v immediately thereafter before sacrifice. Pulse sequential (Pulse, S) animals received $2 \mathrm{~d}$ of BbR0071 and then $2 \mathrm{~d}$ of Lp299v before sacrifice with water in between. Values represent mean $\pm \mathrm{SD}, n=32$ total, $* p<0.001$.

trols (Fig. 2, C1) and tissue collected after Lp299v administration for $20 \mathrm{~d}$ (Fig. 2, C3).

Muc3 mRNA up-regulation is sustained using pulse probiotic administration. With the time-limited effect of Muc3 modulation from a single agent probiotic by $10 \mathrm{~d}$, we tested the effects of varying the strain administered and time course. With a single probiotic agent (i.e. Lp299v) administered for $10 \mathrm{~d}$, jejeunal $M u c 3$ expression at $10 \mathrm{~d}$ was similar to control animals receiving water only $(89 \%$ control \pm 30 , Continuous, SA in Fig. 7). With the daily ingestion of BbR0071 given over a period of $10 \mathrm{~d}$ followed sequentially by Lp299v for $2 \mathrm{~d}$, there was a failure to sustain Muc3 mRNA expression above control animals receiving sterile water ( $111 \%$ control \pm 33 , Continuous, S in Fig. 7). However, both Muc3 gene and protein expression were increased after $2 \mathrm{~d}$ BbR0071 and then $8 d$ of water followed by $2 \mathrm{~d}$ Lp299v (Fig. 2, C4; Fig. 7, Pulse, S, $189 \%$ controls $\pm 15 \%, p<0.001)$. We did not detect a significant effect using pulsed single agent protocol; that is, $2 \mathrm{~d}$ of Lp299v $10^{7} \mathrm{CFU} / \mathrm{d}$ followed by $8 \mathrm{~d}$ of sterile water followed by $2 \mathrm{~d}$ of $10^{7} \mathrm{CFU} / \mathrm{d} \mathrm{Lp} 299 \mathrm{v}$ before killing. Nor did we notice any additive effect with the concurrent addition of both BbR0071 and LIR0011 with respect to $M u c 3$ or $M u c 2$ expression above levels achieved using a single probiotic agent.

\section{DISCUSSION}

This study provides evidence for the modulation of potentially protective mucosal barrier genes in the intestinal tract with a mature established microbiota after oral ingestion of live probiotics. Muc2 and Muc3 are two different mucin genes in the rat intestine with human homologues that both exist as secreted glycoproteins (10-12). Muc3 gene and protein expression was induced in the jejunum and ileum after oral administration of with adherent, live viable probiotic strains Lp299v, BbR0071, and LrR0011 but not using the nonadherent Lpadh- derivative (Figs. 1 and 2). Heat-killed, nonviable
Lp299v was also unable to boost Muc3 transcript expression (Fig. 1). Dead cells of probiotics exert a number of biological responses during in vitro cell-culture and in vivo animal studies (13). However, several of the effects exerted by live strains on IECs are notably absent with dead cells, such as maintaining barrier function after an enteropathogen insult and colonization resistance after enteropathogen adherence $(14,15)$. Dead cells also fail to prevent against cytokineinduced apoptosis (16) and have shown to have inferior efficacy in clinical trials in reducing translocation (17) compared with live, viable probiotics. These reports are in keeping with our findings of live, viable probiotics are necessary to enhance protection of IEC through up-regulation of mucin secretion at the mucosal-luiminal interface. Moreover, comparison of live viable probiotic strains with heat-killed strains report benefit of live viable probiotics, and in some cases, heat-killed probiotics have been associated with increased adverse events such as diarrhea in children (17). Taken together, it seems that some of the beneficial effects of probiotics may be compromised by heat inactivation.

One of the basic properties of probiotics is a low invasive potential, and so one could ask why the host would need to mount a sustained protective response to such microbes. Accordingly, we found that increased Muc3 mucin secretion was not a sustained response. The probiotic-induced increase in Muc 3 expression rose quickly but was falling by $5 \mathrm{~d}$ of oral administration and returned to baseline levels by $10 \mathrm{~d}$ demonstrating a time-limited effect (Fig. 6). A time-limited effect of probiotics has been similarly noted in other studies. One such study reports that histological and gene expression changes of various cytokines induced by $L$. reuteri in the mouse intestine were optimal following $6 \mathrm{~d}$ of oral probiotic treatment but had significantly decreased by $8 \mathrm{~d}$ and fallen to control levels by $21 \mathrm{~d}$ (18). A time-limited inflammatory response has also been indirectly detected through measurement of the nondegradable neutrophil-derived protein calprotectin (19). Thus, responses involving various aspects of the host mucosal protective response seem to be activated but time limited. Although probiotic-induced up-regulation of mucin expression is not a sustained response, it is reproducible. With an 8-d break from the daily administration of a probiotic organism, increased mucin expression is again detected (Figs. 2 and 7).

Studies have consistently demonstrated a modest reduction in the number of stools and length of illness with probiotic treatment of viral gastroenteritis (20). Mucins can both limit access of the viral particle to the epithelial cells and reduce viral replication (21) and it follows that enhanced mucin expression would play a role in limiting the disease process. Improved efficacy of using probiotics as a protective intervention will likely need to account for timing of infectious exposure which may be a difficult task except in more controlled circumstances.

We demonstrated an increased expression of Muc3 mucin in the rat small intestine after the oral administration of both $10^{7}$ and $10^{9} \mathrm{CFU}$ of Lp299v per day (Fig. 4). It would seem as though the effect of probiotic-induced gene modulation does not represent a linear relationship to dose. This is sup- 
ported by clinical dose trials for the prevention of acute infectious rotavirus where it was found that a dose of $10^{6}$ CFU/d has the equivalent efficacy as a greater inoculum administered. However, the underlying disease process and site in gastrointestinal tract may be important for dosing considerations. We did not find that probiotic ingestion of either $10^{7}$ or $10^{9} \mathrm{CFU}$ over a day in the drinking water altered colonic mucin expression. Intragastric bolus feeding of $3 \times$ $10^{9} \mathrm{CFU} / \mathrm{d}$ into rats did increase the $M u c 2$ gene expression (22). Hence, it would seem as though substantially larger oral inoculums eventually provide sufficient numbers of bacteria to reach the distal colon. Accordingly, we observed that the rectal application of $\mathrm{Lp} 299 \mathrm{v}$ did in fact up-regulate Muc2 expression compared with pure water control (Fig. 3). Interestingly, a time-limited effect was also reached by $7 \mathrm{~d}$ in accordance with the up-regulation of small intestinal Muc3 expression via oral dosing. Although Bifidobacteria strains are generally isolated from colonic sites, we have shown that they are equally active in modulation of the small intestinal gene Muc3. This demonstrates that site accessibility and the time of probiotic exposure may be pertinent rather than site of microbial origin when it comes to probiotic-induced IEC interactions.

Secreted factors from the probiotic strain L. rhamnosus GG have previously been shown to prevent cytokine-induced apoptosis in both human and mouse IEC (16) involving both p38 MAPK and Akt, but it is unknown as to whether IAPs are involved. Not surprisingly, our study finds evidence that the transient modification of intestinal gene and protein expression is not specific to mucin genes alone. After $2 \mathrm{~d}$ of probiotic oral ingestion, two of the IAPs studied were up-regulated in rat intestinal tissue of the small intestine (Fig. 5).

NAIP is highly expressed in intestinal villi (23) and evidence is emerging for it being an intracellular pathogen receptor, chiefly for flagellin. Although none of bacteria in this study are flagellated, past work has shown NAIP modulation lies downstream of the TNF pathway (24) and it may be that probiotic modulation of TNF- $\alpha$ (25) elicited the IAP elevation observed in our animals.

In summary, we find that live viable probiotics can induce innate protective mechanisms of the IEC in a reproducible but time-limited manner and speculate that pulsed administration of probiotics rather than continuous probiotic ingestion on a daily basis may enhance some of the protective host responses, further optimizing the benefit derived from their use.

\section{REFERENCES}

1. Madsen K, Cornish A, Soper P, McKaigney C, Jijon H, Yachimec C, Doyle J, Jewell L, De Simone C 2001 Probiotic bacteria enhance murine and human intestinal epithelial barrier function. Gastroenterology 121:580-591
2. Mack DR, Ahrne S, Hyde L, Wei S, Hollingsworth MA 2003 Extracellular MUC3 mucin secretion follows adherence of Lactobacillus strains to intestinal epithelial cells in vitro. Gut 52:827-833

3. Mack DR, Michail S, Wei S, McDougall L, Hollingsworth MA 1999 Probiotics inhibit enteropathogenic $E$. coli adherence in vitro by inducing intestinal mucin gene expression. Am J Physiol 276:G941-G950

4. Elmore S 2007 Apoptosis: a review of programmed cell death. Toxicol Pathol 35:495-516

5. Gyrd-Hansen M, Meier P 2010 IAPs: from caspase inhibitors to modulators of NF-kappaB, inflammation and cancer. Nat Rev Cancer 10:561-574

6. Liévin-Le Moal V, Servin AL 2006 The front line of enteric host defense against unwelcome intrusion of harmful microorganisms: mucins, antimicrobial peptides, and microbiota. Clin Microbiol Rev 19:315-337

7. Allen SJ, Okoko B, Martinez EG, Gregorio GV, Dans LF 2004 Probiotics for treating infectious diarrhoea. Cochrane Database Syst Rev 2:CD003048

8. Johansson ML, Quednau M, Ahrne S, Molin G 1995 Classification of Lactobacillus plantarum by restriction endonuclease analysis of total chromosomal DNA using conventional agarose gel electrophoresis. Int J Syst Bacteriol 45:670-675

9. Khatri IA, Specian RD, Forstner JF 2001 Characteristics of rodent intestinal mucin Muc3 and alterations in a mouse model of human cystic fibrosis. Am J Physiol Gastrointest Liver Physiol 280:G1321-G1330

10. Khatri IA, Forstner IF 1993 Suggestive evidence for two different mucin genes in the rat intestine. Biochem J 294:391-399

11. Ohmori H, Dohrman AF, Gallup M, Tsuda T, Kai H, Gum JR Jr, Kim YS, Basbaum CB 1994 Molecular cloning of the amino-terminal region of a rat MUC2 mucin gene homologue. J Biol Chem 269:17833-17840

12. Wang R, Khatri IA, Forstner JF 2002 C-terminal domain of rodent intestinal mucin Muc3 is proteolytically cleaved in the endoplasmic reticulum to generate extracellular and membrane components. Biochem J 366:623-631

13. Adams CA 2010 The probiotic paradox: live and dead cells are biological response modifiers. Nutr Res Rev 23:37-46

14. Sherman PM, Johnson-Henry KC, Yeung HP, Ngo PS, Goulet J, Tompkins TA 2005 Probiotics reduce enterohemorrhagic Escherichia coli O157:H7- and enteropathogenic E. coli O127:H6-induced changes in polarized T84 epithelial cell monolayers by reducing bacterial adhesion and cytoskeletal rearrangements. Infect Immun 73:5183-5188

15. Michail S, Abernathy F 2003 Lactobacillus plantarum inhibits the intestinal epithelial migration of neutrophils induced by enteropathogenic Escherichia coli. J Pediatr Gastroenterol Nutr 36:385-391

16. Yan F, Polk DB 2002 Probiotic bacterium prevents cytokine-induced apoptosis in intestinal epithelial cells. J Biol Chem 277:50959-50965

17. Sanders ME, Akkermans LM, Constable A, Haller D, Hasmmerman C, Heinbach J, Hormannsperger G, Huys G, Levy DD, Lutgendorff F, Mack D, Phothirath P, Solano-Aguilar G, Vaughan E 2010 Safety assessment of probiotics for human use. Gut Microbes 1:164-185

18. Hoffmann M, Rath E, Holzlwimmer G, Quintanilla-Martinez L, Loach D, Tannock G, Haller D 2008 Lactobacillus reuteri 100-23 transiently activates intestinal epithelial cells of mice that have a complex microbiota during early stages of colonization. J Nutr 138:1684-1691

19. Kuitunen M, Savilahti E 2009 Pro- and prebiotic supplementation induces a transient reduction in hemoglobin concentration in infants. J Pediatr Gastroenterol Nutr 49:626-630

20. Vandenplas Y, Salvatore S, Vieira M, Devreker T, Hauser B 2007 Probiotics in infectious diarrhoea in children: are they indicated? Eur J Pediatr 166:1211-1218

21. Yolken RH, Ojeh C, Khatri IA, Sajjan U, Forstner JF 1994 Intestinal mucins inhibit rotavirus replication in an oligosaccharide-dependent manner. J Infect Dis 169:1002-1006

22. Caballero-Franco C, Keller K, De Simone C, Chadee K 2007 The VSL\#3 probiotic formula induces mucin gene expression and secretion in colonic epithelial cells. Am J Physiol Gastrointest Liver Physiol 292:G315-G322

23. Maier JK, Balabanian S, Coffill CR, Stewart A, Pelletier L, Franks DJ, Gendron NH, MacKenzie AE 2007 Distribution of neuronal apoptosis inhibitory protein in human tissues. J Histochem Cytochem 55:911-923

24. Thompson C, Gary D, Mattson M, Mackenzie A, Robertson GS 2004 Kainic acid-induced NAIP expression in the hippocampus is blocked in mice lacking TNF receptors. Brain Res Mol Brain Res 123:126-131

25. Pagnini C, Saeed R, Bamias G, Arseneau KO, Pizarro TT, Cominelli F 2010 Probiotics promote gut health through stimulation of epithelial innate immunity. Proc Natl Acad Sci USA 107:454-459 